\title{
Recent Literature about Urban Sprawl: A Renewed Relevance of the Phenomenon from the Perspective of Environmental Sustainability
}

\author{
Fernando Rubiera-Morollón ${ }^{1, *(D)}$ and Ruben Garrido-Yserte 2 (D) \\ 1 REGIOlab-Regional Economics Laboratory, University of Oviedo, 33006 Oviedo, Spain \\ 2 University Institute for Economic and Social Analysis, University of Alcala, 28801 Alcalá de Henares, Spain; \\ ruben.garrido@uah.es \\ * Correspondence: frubiera@uniovi.es
}

Received: 19 June 2020; Accepted: 11 August 2020; Published: 13 August 2020

check for updates

\begin{abstract}
The urban sprawl phenomenon has attracted the attention of social researchers since the mid-20th century. It seemed that all relevant aspects had been extensively studied and that it would be difficult to produce new studies with significant contributions. However, in the last decade, we have witnessed a revival of the literature on urban sprawl for three main reasons: (i) the existence of new methodologies to measure the phenomenon based on digital cartography and geo-referenced information, (ii) new hypotheses about the relevance of the formation of metropolitan areas not institutionally integrated into urban sprawl in many places and, mainly, (iii) the role of urban density in the environmental sustainability of cities. The recent literature on this third aspect has grown the most and around which it seems that new and interesting lines of future research will develop. The objective of this work is to present a synthetic review of the most recent literature on urban sprawl as of the end of the second decade of the XXI century. This review can serve to recapitulate the growing consensus that is being formed on the lower environmental sustainability of low-density cities and diffuse limits.
\end{abstract}

Keywords: urban sprawl; urban sustainability; urban planning; energy efficiency; urban mobility and residential location decisions

\section{Introduction}

Cities allow us to work, create, have fun, and express ourselves together while sharing urban spaces. However, the concentration of the population and economic activity in a reduced space generates waste and environmental impacts. Cities are successful when they are able to maximize contact and interaction, facilitating the generation of ideas and the dissemination of knowledge while providing an environment that saves energy and resources and minimizes the environmental impact. There are many elements that interact, making a city more or less sustainable, more or less creative, and in short, more or less successful. The interaction of these elements affects the level of education of citizens, the structures and institutions that facilitate economic and social interaction, demographic and cultural aspects, and purely geographical factors. Nevertheless, purely urban elements, such as the configuration of the city, the existence of adequate urban spaces for interaction, the dynamism of the city centre or its density, also have an impact. One of the urban aspects that has generated the most attention is the phenomenon of the physical expansion of cities accompanied by a significant loss of density, known in the international literature as urban sprawl.

Jane Jacobs, in her great work "The death and life of great American cities" [1], was one of the first authors to call attention to the inefficiency of the dispersed city model that was prospering in North America. This model was based on the promotion of peripheral and dispersed residential 
neighbourhoods for which development took place together with heavy investment in highways designed to support a very large number of automobiles. Jacobs explains, with extraordinary clarity, how this type of city destroys social and cultural life, leading to less creative and more dangerous environments. From the 1960s to the present day, a vast body of literature on the delimitations, causes and consequences of sprawl has proliferated. At the end of the last century, it seemed that the phenomenon was already widely studied in all its possible aspects, see [2] for a revision. However, in recent years, we have witnessed a resurgence of the academic literature related to sprawl.

There are several reasons why this renewed interest in the physical configuration of cities in general and the phenomenon of their scattered growth, in particular, has occurred. On the one hand, new methodologies have been developed for cartographic digitization and the treatment of geo-referenced information. These new techniques and databases have allowed a much more precise analysis of the sprawl and the design of new indicators. Therefore, theories about the origin of sprawl and the causes of its global growth have been revised with a more precise empirical approach. However, the main reason why this phenomenon has once again attracted the attention of urban planners and social scientists is because of the close relationship that exists between sprawl and the environmental efficiency of cities. Under this perspective, interesting works have appeared that analyse the environmental consequences of sprawled urban growth. In addition, most of the new contributions consider large cities in the emerging countries of Latin America or Asia. The transformation of many European cities is also being explored. All this allows us to obtain new and relevant conclusions about a phenomenon that continues to be central among urban planners, geographers and urban economists.

The objective of this work is to offer a brief review of some of the most recent research. Our interest is not to present a systematic review of the extensive literature accumulated in decades of research on urban sprawl and the physical configuration of cities. We seek only to identify the novel elements that explain the resurgence of academic interest around this phenomenon. The search engines of Scimago-Scopus, Web of Science and Google Academics have been used to select the works that have generated the greatest impact or can be considered as more innovative focusing in the recent literature, mainly since 2000 and especially during the last decade (2010-2020).

This review has been structured in three sections, in addition to the introduction and conclusions. In Section 2, we review how, thanks to the development of cartographic digitization or georeferencing systems, the measurement has changed and, as a consequence, the conceptual delimitation of the urban sprawl has also changed. Section 3 reviews the most recent works on the causes of sprawl, which undoubtedly take advantage of technical improvements in its measurement. Finally, Section 4 provides the analysis of the consequences of sprawl, focusing especially on the aspect that is generating the most interest: the relationship between urban sprawl and the environmental sustainability of cities. The work ends with a final section of conclusions and policy implications.

\section{Revision of the Definition of Urban Sprawl Motivated by the Development of New Techniques for Its Measurement}

Studies on urban sprawl were first conducted by urban planners who approach the phenomenon from a multidisciplinary perspective. It is understood that urban sprawl is not only a physical phenomenon of the dispersion of buildings and expansion of the space occupied by the city but also a phenomenon that encompasses different disciplines: geography, urban planning, environmental analysis, economics, sociology and even policy science [3]. The consideration of these many elements has led to numerous definitions that try to encompass the complexity and multidisciplinary nature of the urban sprawl phenomenon. Sometimes these definitions are inconsistent with one another, thereby leading to confusion [4].

One of the main goals in the recent literature about urban sprawl has been to provide a precise definition of the concept, which might also lead to quantitative research. In this line, one of the first contributions was made by Galster and colleagues [5] and Squires [6], who provided a definition that manages to encompass the complexity and multidimensionality of the phenomenon of urban 
sprawl. In [4], urban sprawl is defined as "a pattern of land-use in an urban area that exhibits low levels of some combination of eight district dimensions: density, continuity, concentration, clustering, centrality, nuclearity, mixed used and proximity". In a similar way, in [4], sprawl is defined as "pattern of urban and metropolitan growth that reflects low density, automobiles-dependent, exclusionary new development of the fringe of settled areas often surrounding a deteriorating city".

In 2004, Glaeser and Kahn [2] compiled one of the most complete reviews of the leading papers on urban sprawl and its consequences, defining sprawl in a way similar to that proposed by Galster and colleagues and Squires [4,5] and taking into consideration the different aspects that interact in a sprawled city. Other examples of definitions considering these multidimensional perspectives are those given by Dwyer and Childs [7] connecting sprawl with centres' decline; Sturm and Cohen [8], focusing mainly on the public-health effects; or Davoudi [9], taking the environmental perspective.

In the aforementioned references, a multidimensional perspective is used to define the urban sprawl phenomenon. Furthermore, causes and consequences are included as part of the definition of the phenomenon. Although this allows us to have a definition capable of containing the complexity of the phenomenon, it makes it more difficult to arrive at an appropriate indicator based on it. For this reason, other authors have chosen to define the phenomenon of urban sprawl by focusing on its physical dimension and isolating it from its socio-economic causes and consequences. For example, Peiser [10] pointed out that sprawl is defined with a more spatial perspective as "a gluttonous use of land, uninterrupted monotonous development, leapfrog discontinuous development and inefficient land-use".

Recent contributions, such as the one made by Jaeger and colleagues [11,12], have gone further in this respect, paying attention only to three dimensions: dispersion, the ratio of built-up area and the density of use. Urban sprawl is understood as a phenomenon that can be visually perceived in the landscape: "the more area that is built up and the more dispersed the buildings, the higher the degree of urban sprawl" [12]. Departing from this way of defining the sprawl, it is relatively easy to construct quantified measures of it. Specifically, in Jaeger and Schwick [12] an indicator that considers the three dimensions mentioned above is proposed, although it still presents serious problems of subjectivity in the weightings applied and in the choice of the dimensions used.

The transformation of the diffusion of sprawl has stemmed from the development of geo-referenced analysis techniques. During the 2000s, there was an extraordinary development of digital cartography and geo-referenced databases. Photogrammetric techniques and the ability to interpret and analyse orthophotos were developed. All this opens up extraordinary possibilities to study the phenomenon of sprawl from a physical perspective. Some authors thus begin to distinguish the physical phenomenon from its environmental, economic, social or political consequences. This distinction between the physical phenomenon, now easily measurable and internationally comparable, and its multidimensional consequences has helped research take a great leap forward to better understanding urban sprawl.

Among the first authors identifying the potential of simplifying the definition of sprawl to measure it in a more objective and comparable way were Burchfield and colleagues [13]. These authors define urban sprawl as "whether the residential development is scattered or compact", such that "in the sprawling areas much of the land immediately surrounding the average house will not itself be developed". This narrows the definition of urban sprawl down to only one dimension, the degree to which buildings are dispersed, thus simplifying quantification. These authors propose an Urban Sprawl Index (USI) coherent with their definition, which can be obtained via the possibilities offered by new digital cartography and photogrammetric techniques. This new technique allows for delimiting each pixel of the image as an urban area or as unbuilt or rural spaces. Once the pixels built in the urban environment are delimited, we can trace a circle with a radius of one $\mathrm{km}$ and count the number of other urban pixels that fall on it. The USI is obtaining by the aggregation of the values of all pixels in a specific area. High values of USI (up to 100) values indicate high levels of sprawl, while low values indicate concentration [13]. See Figure 1 as an example of the application of this approach to the metropolitan area of Madrid. The precision of the new digital cartography and photogrammetric 
treatment techniques allows us to identify buildings and the distance between them and to calculate an objective dispersion index for the metropolitan area or for each of the municipalities or sub-areas, as shown in Figure 1.

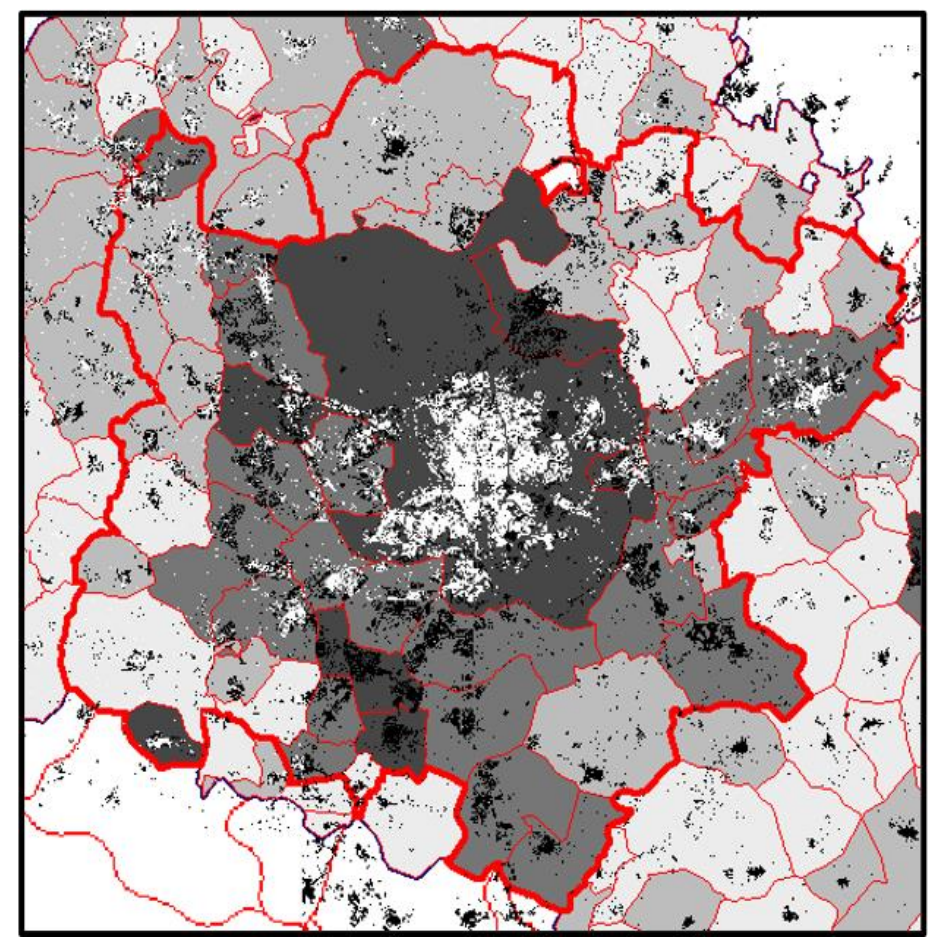

Borders of the Metropolitan area of Madrid

Municipalities borders

\section{Urban sprawl index by municipalities:}

40-50 (8)

50-60 (25)

$60-70(46)$

$>70$ (114)

Figure 1. Example of the application of Burchfield and others [13]'s urban sprawl index in the case of the metropolitan area of Madrid (Spain) (2011). Source: own.

The paper of Burchfield and colleagues [13], has had a major impact, and the approach used by these authors has spread to the spheres of both geography and urban economics-See Rubiera and others [14] as an example-With the subsequent publication of a large number of papers based on the original idea proposed by Burchfield and others [13]. Some of this research has broadened the scope of analysis to aspects of urban morphology or the structure of cities. Once such a simple definition is available associated with an analysis technique of the degree of sprawl, we can carry out international studies of urban sprawl opening the door to comparative quantified analyses of the consequences of urban sprawl.

\section{Recent Contributions on the Identification of the Causes of Urban Sprawl: Policy also Matters}

Regardless of the definition that is applied, urban sprawl is spreading globally, and an increasing number of cities in the world are sprawling to a greater or lesser extent. The first cities that began to experience scattered growth were those in the central and western United States [15]. However, this urban model was quickly imported into Latin America, as Gilbert [16] or Polèse and Champain [15] show, and later, in several Asian cities, as reflected by Bunnell [17]. Today, urban sprawl is a global phenomenon.

It is clear that the diffusion of vehicles as a means of transport is behind the increase in sprawl. The cities that first and most intensely experienced the tendency to disperse are those that grew when cars began to occupy their streets and avenues, affecting urban design and the way these cities grew. However, even though an automobile relativizes the importance of distance, the logic of maintaining a compact city should continue to remain relevant, even if its dimensions are extended. However, what is observed is that as cities expand, their centres weaken and their boundaries blur. In other 
words, we did not observe a modification of the logic of urban growth associated with new technology but a profound paradigm shift in the configuration and characteristics of the city.

The average income level affects residential decisions and subsequently, the urban form and the level of sprawl [6]. In rich countries, the floor area occupied per person is on average two to three times higher than that of developing countries. This factor, in the absence of any other change, is often sufficient to explain why the physical extent of cities doubles or triples as the country develops.

In short, even without population growth, the physical expansion of a city appears to be an inevitable consequence of development. Dispersion has nested so strongly in Latin American cities because they have experienced very intense growth. As an illustration, Figure 2 shows the expansion that the city of Quito (Ecuador) experienced during the period from 1983 to 2015, a phase of strong economic growth in the area. Before 1983, the city was in the area delimited by the red stripe. By 2015, it had expanded to more than double its original size, invading a wide space in the surrounding area, especially on the eastern axis.

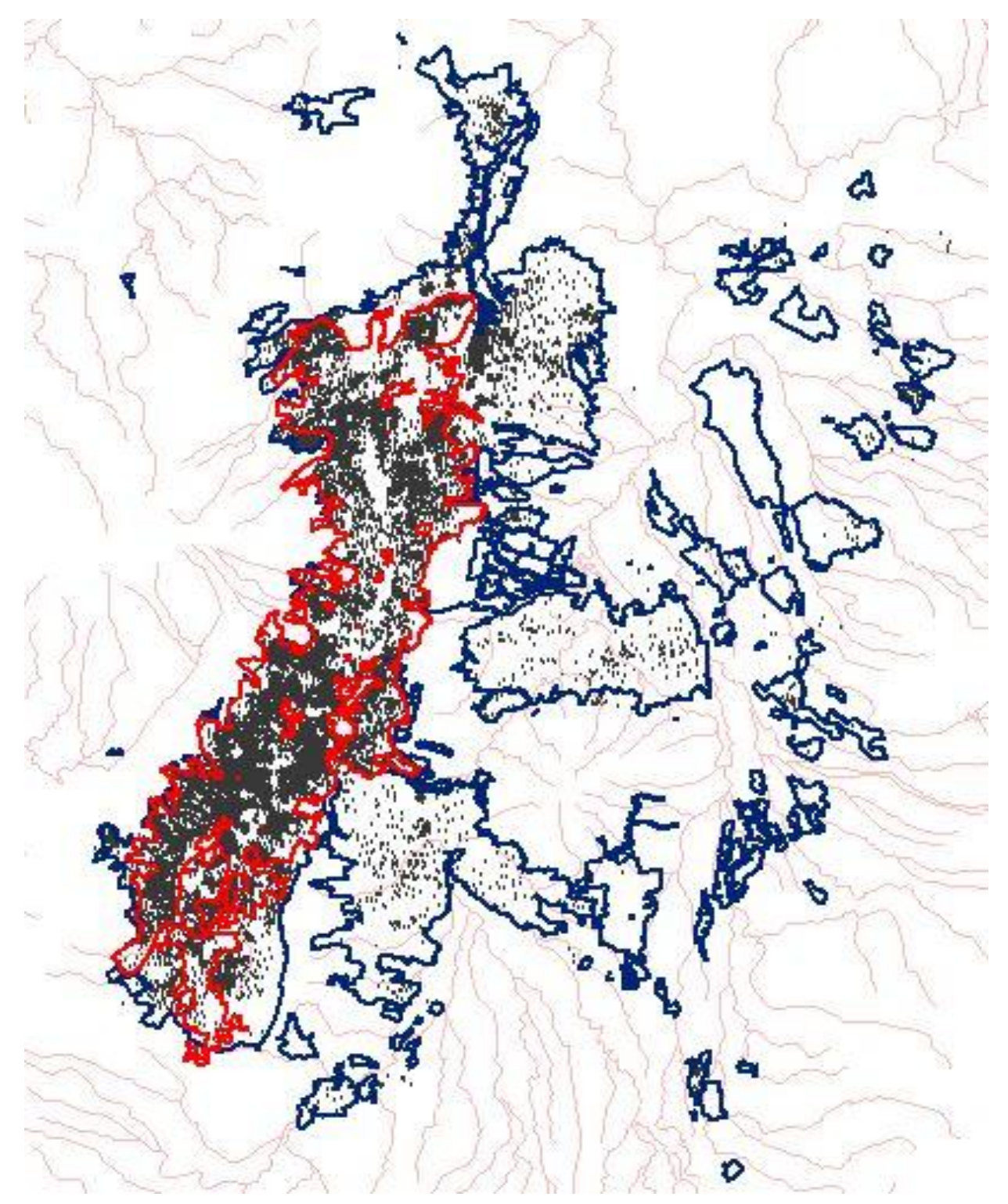

Figure 2. Example of urban sprawl expansion in a developed city: the case of Quito (Ecuador) $(1983,2015)$. Source: own. 
What factors could counterbalance this effect? It is clear that the element that can most restrain the urban sprawl trend is a very strong and dynamic centre. Only a centre that generates employment, economic and social activity and intense cultural life can make families value the proximity to such a special place in their daily life, slowing down the process of extreme expansion of a dispersed city. However, the problem is that dispersion, along with other frequent actions or policies in our time, affects the strength of the centre.

The dynamism of the centre is, therefore, the main compacting element of a city. If it weakens, it will facilitate an accelerated dispersal process [15]. However, the centres of many cities are in danger or have already experienced a decline. This decline occurs most in the United States but also in Latin America, and signs of damage are beginning to be identified in the centres of European cities. A review of the cases affected by the weakening of the city centre can be found in $[15,18,19]$, among others.

Among the factors that can affect the "health" of the centre, we can highlight the following:

(i) The layout of the communication and transport routes does not promote the retention of the historic centre. In Montreal, for example, the metro (built in the 1960s) increased accessibility to more modern neighbourhoods located north of "Old Montreal", thus speeding up the process of the marginalization of the old business district [15].

(ii) Protecting the architectural and urban heritage of the centre makes it difficult to expand the supply of office spaces and limits the densification of the centre, so less central areas meet the demand. In many countries, there are several examples of cities with protected historic quarters, causing growth in the more modern areas of the cities [18].

(iii) There are social tensions in cities for different reasons, which are manifested in high rates of crime and violence so that companies and offices seek other locations. It is on this point that the cities of the United States are distinguished from other cities of the industrialized world [15]. However, social tension is an element that should not be neglected in various cities in Latin America [19].

(iv) The division of the urban space into different local political or administrative units without a system of fiscal equalization creates "artificial" differences at the level of taxes and the quality of public services. If the centre is located in a municipality that has fiscal problems, it will be less attractive. Again, this situation is prevalent in North American urban regions. New York City, for example, imposes a higher tax burden (on income and on real estate) on its inhabitants than most of the surrounding municipalities [20].

One of the main lines on which the most recent research on the causes of urban sprawl has focused is related to point (iv). For example, LeRoy and colleagues [21] show that the fragmentation into different political-administrative units of an integrated urban space usually brings with it a dynamic of urban sprawl. It can be deduced from most of these analyses that in terms of urban policy, it is convenient to avoid the processes of political fragmentation within locally integrated spaces. However, it is possible that fragmented space results from the growth of cities that were previously independent: the conurbation processes lead to the formation of especially complex metropolitan areas. In Europe, and more specifically in Spain, it is increasingly common to find this type of metropolitan area or conurbation that arises from the growth of urban centres close to each other. The European Observation Network, Territorial Development, and Cohesion (ESPON) has developed a polycentrism index and a map of Urban Functional Areas (hereinafter, FUAs) and Metropolitan European Areas of Growth (MEGAs) showing up to 110 cases of varying intensity throughout Europe (ESPON, 2005). There are very few cases in which supra-municipal coordination policies exist. Most of the attempts to establish common policies in the local area fail. One of the clearest cases of a metropolitan area emerging from several urban nuclei of very similar size to each other is the case of the central area of Asturias, which is comprehensively studied by González and others [22]. Another example is the Madrid metropolitan expansion that analysed by Rubiera and others [23].

For example, the study carried out by Rubiera and others [23] on Madrid confirms how its metropolitan area tends to expand towards the periphery before the pressure on land-use in the areas 
closest to the centre forces it to do. In other words, the most remote municipalities are the ones that are growing the most although there is abundant space for urban growth in the closest municipalities (see Figure 1 for an illustration). Furthermore, municipalities on the periphery tend to grow dispersedly. In other words, we observe that Madrid is following a city model of unwarranted dispersion and expanded development towards the periphery, even beyond the limits of the officially defined metropolitan area. The authors claim that the main reason for this predatory land dynamic is competition among peripheral municipalities to attract the population. The population volume of a municipality is, along with construction activity, the main source of financing for municipalities in Spain, especially for the smallest municipalities, which have more freedom in their urban policy. In the Madrid region, there are very few limitations to the classification of land as developable, with few protected spaces, which has facilitated the competition to attract residential construction, causing an expanded urban growth pattern that endangers the traditional urban balance of Madrid.

Nevertheless, an urban sprawl process could be followed by the patterns of dispersion and polycentrism, which appear in various areas of the metropolis from a functional approach. The subcentres of employment have the ability to structure the metropolitan operation and exercise different degrees of influence in the respective centres and corridors. However, the central city plays a structuring role mainly in relation to the labour flows in higher skilled and trained occupations, see Usach and others [24]. The complexity of these processes must be considered in the formulation of public policies designed to mitigate the unwanted impacts of the dispersion, while the sub-centres of employment are consolidated to articulate metropolitan dynamics.

\section{Consequences of Urban Sprawl: The Renewed Relevance of the Topic from the Perspective of Urban Sustainability}

The first studies on urban sprawl were more attentive to describing the phenomenon and understanding its causes than to analysing its consequences. However, the debate about the effects of the dispersion of cities soon began. In Jenks and others [25] and Bruegmann [26], a comprehensive review of this first stage of the international literature on urban sprawl is presented. In this first phase, sprawl was understood to imply soil predation with consequences on the natural environment of cities and generated greater distances in the city, which made mobility more difficult. However, there was no consensus among social scientists about the ultimate impact of the phenomenon. Some researchers argued that urban sprawl was an inevitable consequence of economic growth and the development of societies that could have positive effects. For example, Ewing [27] argued that a dispersed city promoted lifestyles that reconnected human beings with nature without having to abandon the advantages of urban life, and Breheny [28] positively valued the creation of large and polycentric cities that subsequently achieved a more efficient distribution of economic and social activity, avoiding congestion around a single centre.

As more cities sprawled or did so with greater intensity, more evidence accumulated on the effects of this urban model. In parallel, we have witnessed an extraordinary improvement in the methodologies used to capture information. All this has given rise to much more precise empirical studies that have clarified the effects of dispersion on various fields and reached a greater consensus among the scientific community on the lower social and environmental sustainability of dispersed cities. Two good reviews of the literature on this second phase can be found in Camagni and colleagues [29] or Wilson and Chakraborty [30].

Already from a position of consensus against the dispersed urban model, although with nuances according to each author, the literature has continued to advance in the last decade, paying attention to four main issues:

(i) social or economic effects of sprawl

(ii) immediate environmental impact of sprawl through urban extension, soil predation or landscape effects

(iii) relationship among sprawl, mobility and sustainability 
(iv) relationship among sprawl, climate change, energy efficiency and urban sustainability

These topics are studied in cities around the world, although there has been a logical growing interest in studying the phenomenon in the emerging economies of Latin America and, mainly, Asia.

Regarding the first topic mentioned, the relationship between urban sprawl and other social and economic aspects, there has been abundant international scientific production that has allowed us to better understand how the phenomenon of the dispersion of cities affects multiple aspects of social behaviour and daily life, some of them not at all obvious. For example, Briggs [31], among others, has shown that urban dispersion increases social conflict in cities. The coexistence of different social classes that, in most cases, coincide with ethnic groups or religions, in dispersed cities with run-down main centres, facilitates the generation of enormously dangerous urban ghettos. With analysis from a historical perspective, Axelrod [32] has shown how a dispersed city has greater difficulty integrating immigrants and facilitating the assimilation of new cultures. From another perspective, Florida and Mellander [33] paid attention to how less integration of urban life generated by dispersed cities with weak centres translates into less capacity to generate the positive effects of agglomeration on creativity, talent or cultural development. Other authors, such as Frumkin [34], explore the effect of dispersion on health. The dispersed city model leads to intensive use of the automobile, reducing physical activity and facilitates, when combined with other factors, an increase in obesity and subsequent health consequences; see, among others, Sole-Ollé [35]. Finally, there are several works that relate urban dispersion with taxation. In Kotchen and Schutle [36], an extensive literature review with a meta-analysis that synthesizes the conclusions of 125 different studies of the relationship between land-use and the local fiscal situation is carried out. The main conclusion is that an increase in population with an increase in urban density improves the fiscal situation of local governments. However, when the population increases without an increase in density, the effect usually translates into a worsening of the fiscal situation, although it depends on other conditions linked to the local reality. Other authors, see among others [19,37-39], directly study how urban dispersion affects local fiscal stability through econometric analysis. They find that, in general, an increase in urban dispersion is accompanied by an increase in local public debt and, in the medium and long term, a greater fiscal burden.

For the second point mentioned, the immediate environmental impact of the extension of a city and the soil predation produced by its dispersion, the works [40-46], show how dispersion aggressively invades landscapes and damages natural environments. In Slemp and others [44], attention is paid to the damage to the traditional rural culture that, as they point out in their work, is literally exterminated in wide environments around the dispersed city. In Yan [47], this type of impact analysis is applied to Chinese cities with similar conclusions. More recently, Yang and colleagues [48] extend previous conclusions using advanced GIS models that allow us to see the growth in urban sprawl and the simultaneous disappearance of natural spaces.

Despite the relevance of these previous analyses, the most recent literature on the impact of urban sprawl on the environmental sustainability of cities has been more focused on analysing the effects of urban sprawl on mobility or on energy efficiency. In relation to mobility, it is assumed that sprawl implies greater distances and lower population density, which hinder the success of mass transit, either due to the cost of infrastructure in large urban areas, in the case of a subway or commuter rail, or due to the number of necessary stops, which makes urban bus systems very inefficient $[28,49]$. Several studies have analysed how dispersion leads to the deterioration of public transport, leading to complete reliance on private vehicles for mobility [50]. Going beyond this idea, some works have explored how this greater intensity of private transport in dispersed cities ends up affecting the traditional centre [51] and a number of processes: greater dispersion implies greater use of private vehicles and the deterioration of public transport [52]. This change in the transportation mode damages the centre, which, when weakened, loses its ability to stay compact, accelerating the dispersion process [53]. Therefore, a double vicious circle occurs. First, the use of private vehicles as the main means of urban transport causes cities to tend to disperse, but at the same time, this greater dispersion leads to 
increased use of private vehicles [54]. However, the use of a private vehicle damages the dynamism of urban centres, and this weakness of the centre accelerates dispersion [55]. In short, when a city enters the path of greatest dispersion, it simultaneously enters the path of greatest private vehicle use [50]. Inverse reasoning is equally valid: Cities that fail to develop good public transport systems and rely on private vehicles for mobility, experience greater urban dispersion [50]. Only urban models that facilitate the movement of citizens by mass transit, such as buses, trains or subways, efficiently manage the daily mobility of large cities [56]. Private vehicles are one of the main sources of $\mathrm{CO}_{2}$ emissions and other polluting gases and particles that are very harmful both to people's health and to the environment [57]. One of the main causes of global warming is the intensive use of cars as the main means of urban transport by an excessively large percentage of the world's urban population [58]. In recent years, most recent research has paid attention to the complexity of mobility in dispersed cities in emerging countries in Latin America—see, among others, Coq and Asian [59]—or in Asia—see, among others, $\mathrm{Xu}$ and colleagues [60]. In general, the conclusion of these works is that city models can provide true solutions to urban mobility problems. Compact cities facilitate the use of public transport by having high population density that is combined with strong centres that act as a point of interaction and interconnection. The distances are shorter, so it is easy to find very healthy and efficient alternatives to private vehicles (see Figure 3).

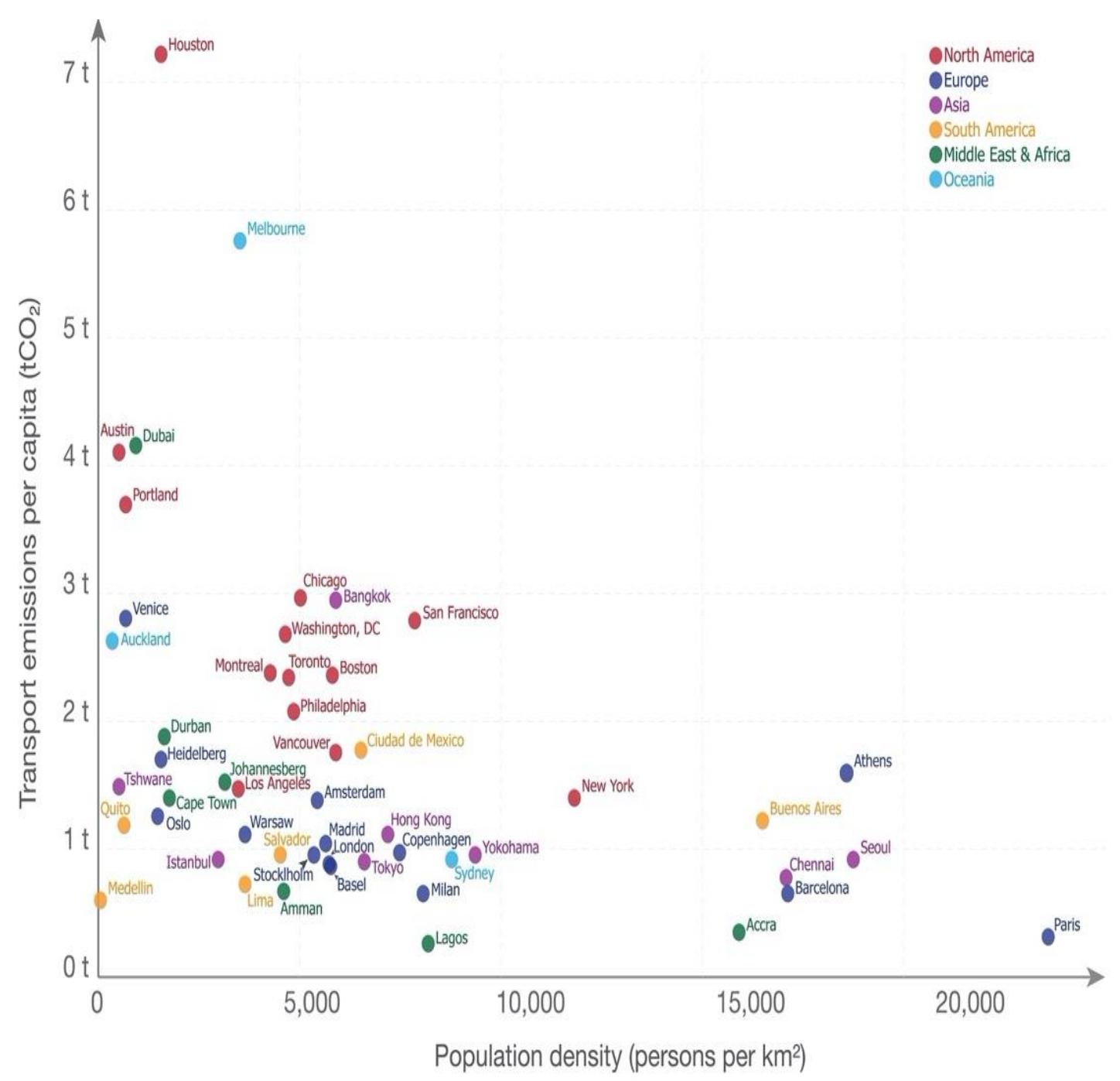

Figure 3. Urban density and carbon emissions per capita (2017). Source: C40 Cities Organization. 
The other main environmental aspect around which the greatest scientific studies have been carried out in recent years is related to the exploration and analysis of the relationship between urban sprawl and energy efficiency from a residential perspective. As examples, see, among others, the works [61-64]. In Lasarte and others [65], a study on 17 regions of Spain is conducted to determine the effects of urban sprawl on electricity demand via quantile regression, reaching similar conclusions for the Spanish case. All these works offer evidence of the lower energy efficiency of typical single-family homes in scattered urban settings. This residential model increases the energy costs borne by families and significantly reduces energy efficiency, which occurs because, first, this model is more complex and makes it more expensive to provide energy through primary sources, regardless of whether it is gas, electricity or another source, to homes located in dispersed urban areas. You have to lay more kilometres of pipelines or power lines at a higher cost and greater loss of resource during transport. This is all required to reach a very low volume of families due to the low density that dispersed growth implies. However, second, and surely more important, single-family homes are a mode of construction that is less energy efficient than apartment/flats. Single-family homes are more exposed to cold or heat, and it is more expensive to maintain the temperature of a house. See Lasarte and others [65] for an extended analysis of this idea.

To finish, it is important to remark that while it is undeniable that higher density can bring numerous positive impacts some studies deal with the negative impacts of density (e.g., crowding, psychological issues, privacy issues, vulnerability to disease spread, etc.). Most of this literature shows an inverted U-shaped curve relationship with a positive impact in the cost-benefits of beginning agglomeration but negative with higher figures. See, for example, Sarkar and Webster [66] and [67] regarding the relevance of combining density with green spaces, pedestrian areas and other facilities to avoid health problems in the city. In the same line, Gruebner [68] highlight the relationship between social isolation and discrimination as well as poverty in the neighbourhood contribute to the mental health burden and the built environment. The negative impacts of density are also linked by competition for space that displaces street life, in the absence of urban planning. Privatizing public space, reduce access to quality goods and services in urban agglomerations and street-life intensity in their cores as is remarked by Dovey and Symons [69]. The general conclusion of these works is compatible with the one that follows from those that have been previously cited: it is desirable that the city has clear limits and a compact development, but ensuring that this compact growth does not mean the generation of cities without spaces large enough for the enjoyment and relaxation of the inhabitants.

\section{Conclusions and Policy Implications}

The phenomenon of urban sprawl has always attracted the attention of urban planners, geographers, urban economists or sociologists. Since the 1960s, there have been numerous studies on the causes and effects of the dispersion of cities. In the late 1990s, there was a consensus around the idea that sprawled cities were less economically and socially sustainable. Then, it seemed that the possibility that scientific works around this topic could no longer make a contribution. However, in the last decade, there has been a resurgence of the scientific literature on urban sprawl.

There are three main reasons why social researchers have turned their attention to the sprawl phenomenon. First, the extraordinary development of digital cartography and geo-referenced information systems in recent years has made it possible to calculate more accurate and internationally comparable indicators on urban form and the level of sprawl. Second, and thanks to these indicators and sophistication of data analysis methodologies, we have witnessed an increase in studies on the causes of sprawl. Most recent works pay attention to the influence that the political-administrative organization ends up having on how cities grow. Finally, but surely the most relevant aspect with the most important future projections, a growing interest in urban sprawl has resurfaced due to the importance that the design of environmentally sustainable cities has acquired in our time. The growing concern about climate change has generated an explosion of multidisciplinary works on energy 
efficiency and environmental sustainability. In this context, we have witnessed a new impetus for the debate on the urban form and its impact on the environment.

In this work, Scimago-Scopus, Web of Science and Google Academic search engines have been used to review recent contributions in this area. Among them, almost 70 bibliographical references were selected for their greater impact or innovative character of the contribution. This is just a selective snapshot of the recent scientific database on urban sprawl and density, a number that is not necessarily representative, yet it still offers the capacity to observe some indicative trends and conclusions. We observe that a dominant view is being formed on the advantages of dense cities with clear limits over the dispersed urban model.

The negative impacts of sprawled cities are not limited to damage to the immediate environment or less sustainable mobility models, which were noted in the literature of the late twentieth century. The residential model of these cities is also less sustainable in terms of energy efficiency. City dispersion negatively affects local fiscal solvency, the quality of life and the health of city inhabitants.

Some clear urban policy recommendations emerge from the conclusions of the extensive literature reviewed, among which we can highlight the following:

(i) Given the relationship between sprawl and the administration of the territory identified by many authors, it seems necessary to coordinate the urban planning and land-use policy of the different municipalities in an integrated urban area. To this end, special guidelines can be developed for areas where urban expansion processes can be identified, covering various local governments. Going further, in places where the interaction between municipalities is especially intense, it is advisable to develop models of metropolitan governance that give institutional protection in the urban reality that is taking place in many places.

(ii) Similarly, it would be convenient to introduce greater restrictions on land-use, especially in small towns located near large cities or metropolitan areas that have natural resources of interest. Likewise, dense and high-rise construction can be promoted in urban plans with urban re-compaction strategies in cases where it is deemed necessary.

(iii) Likewise, urban mobility models supported by public transport should be promoted, to limit the use of private vehicles.

(iv) Several authors relate sprawl to the dynamism of the city centre, which leads us to think about the importance of preserving and promoting the life of the centre, making it the natural place for interactions among the urban population.

(v) It is important to create urban public spaces that facilitate interaction. Green spaces should be promoted because they make cities more attractive and connected with the natural environment; however, it is also important to maintain construction density and clear urban limits.

(vi) Demographic and economic projections should be considered in urban plans so that unjustified expansions due to endogenous dynamism are not promoted.

(vii) Finally, according to various works, it is advisable to modify the local financing system so that it does not generate incentives for scattered growth or urban development in leaps and bounds. Construction fees should be introduced that include the environmental cost of single-family homes or the provision of services in dispersed environments.

There is a tendency to think that the main policies are in the hands of the central or regional governments. However, the provision of essential goods and services needed for the daily quality of life of citizens falls on the backs of local governments. The role of local institutions in environmental sustainability and economic promotion is increasingly important. In many cases, these functions have to be realized with very limited tools, both fiscal and legislative. However, some of the functions that are entirely the responsibility of local governments may have decisive economic and environmental impacts. In the current knowledge society and due to globalization, a city is one of the cornerstones on which the sustainability and competitiveness of our economy rests. A city provides spaces where people interact and where the economic and social activity takes place. There are cities that promote interaction 
and that reduce their environmental impact, while others do not. This is why some cities are creative, innovative, happy, inclusive and sustainable cities, and others are stagnant, boring, sad, uneven and polluting. The success of a city depends on many elements. As a result of the review conducted in this work, we have distilled dominant views regarding the importance of stopping dispersal dynamics and conserving urban density and compact urban growth with clear limits. The literature on specific aspects related to neighbourhood sustainability, urban planning that optimizes the potential of cities or that explores the effects of the shape of the city continues to grow. New revisions on these particular aspects with greater precision are very necessary to define the consensus that the empirical studies are outlining.

Author Contributions: Both authors collaborate equally in all sections. All authors have read and agreed to the published version of the manuscript.

Funding: This research received no external funding.

Conflicts of Interest: The authors declare no conflict of interest.

\section{References}

1. Jacobs, J. The Death and Life of Great American Cities; Hardcover: New York, NY, USA, 1961.

2. Glaeser, E.; Kahn, M. Sprawl and urban growth. In Handbook of Regional and Urban Economics; Henderson, V., Thisse, J.F., Eds.; Elsevier: Amsterdam, The Netherlands, 2004; Volume 4, pp. 2481-2527.

3. Torrens, P. A toolkit for measuring sprawl. Appl. Spat. Anal. Policy 2008, 1, 5-36. [CrossRef]

4. Richardson, H.W.; Chang-Hee, C.B. Urban Sprawl in Western Europe and the United States; Ashgate: London, UK, 2004.

5. Galster, G.; Ratcliffe, M.R.; Wolman, H.; Coleman, S.; Freihage, J. Wrestling sprawl to the ground: Defining and measuring an elusive concept. Hous. Policy Debate 2001, 12, 681-717. [CrossRef]

6. Squires, G.D. Sprawl: Causes and Consequences and Policy Responses; The Urban Institute Press: Washington, DC, USA, 2002.

7. Dwyer, J.F.; Childs, G.M. Movement of people across landscape: A blurring of distinctions between areas, interest and issues affecting natural resource management. Landsc. Urban Plan. 2004, 69, 153-164. [CrossRef]

8. Sturm, P.C.; Cohen, D.A. Suburban sprawl and physical and mental health. Public Health 2004, 118, 488-496. [CrossRef] [PubMed]

9. Davoudi, S. European briefing: Polycentricity in European spatial planning: From an analytical tool to a normative agenda. Eur. Plan. Stud. 2003, 11, 979-999. [CrossRef]

10. Peiser, R. Desconposing urban sprawl. Town Plan. Rev. 2001, 72, 275-298. [CrossRef]

11. Jaeger, J.A.G.; Bertiller, R.; Schwick, C.; Cavens, D.; Kienast, F. Urban permeation of landscapes and sprawl per capita: New measures of urban sprawl. Ecol. Indic. 2010, 10, 427-441. [CrossRef]

12. Jaeger, J.A.G.; Schwick, C. Improving the measurement of urban sprawl: Weighted urban proliferation (WUP) and its application to Switzerland. Ecol. Indic. 2014, 38, 294-308. [CrossRef]

13. Burchfield, M.; Overman, H.G.; Puga, D.; Turner, M.A. Causes of sprawl: A portrait from space. Q. J. Econ. 2005, 121, 587-633. [CrossRef]

14. Rubiera, F.; González, V.; Rivero, J.L. Urban sprawl in Spain: Differences among cities and causes. Eur. Plan. Stud. 2016, 24, 204-226.

15. Polèse, M.; Champain, C. La Evolución de los Centros Urbanos: La Experiencia de América del Norte; World Bank: Washington, DC, USA, 2003.

16. Gilbert, A. The Mega-City in Latin America; United Nations University Press: Tokyo, Japan, 1996.

17. Bunnell, G. Analyzing the fiscal impact of development: Lessons for building successful communities. J. Community Dev. 1998, 29, 38-57. [CrossRef]

18. Polèse, M.; Rubiera, F. Economía Regional y Urbana. In Introducción a la Geografía Económica; Thomson-Civitas: Madrid, Spain, 2009.

19. Rubiera, F; Aponte, E. Retos para el crecimiento equilibrado de la ciudad de Bogotá. El declive del centro y el desamparo de la periferia meridional. Investig. Reg. 2009, 16, 43-71.

20. Varela, L.; Rubiera, F.; Shedrakian, G. Urban Sprawl and local fiscal burden: Analyzing the Spanish case. Empirica J. Eur. Econ. 2019, 47, 177-203. [CrossRef] 
21. LeRoy, G.; Hinkley, S.; Tallman, K. Another Way Sprawl Happens: Economic Development Subsidies in a Twin Cities Suburb; Institute on Taxation and Economic Policy: Washington, DC, USA, 2000.

22. González, V.M.; Rubiera, F.; Pérez, J.L. Dispersión urbana en áreas metropolitanas policéntricas: Análisis del caso asturiano mediante el uso de sistemas de información geográfica. ACE Archit. City Environ. 2014, 8, 38-63.

23. Rubiera, F.; González, V.M.; Pérez, J.L. Urban sprawl in Madrid? An analysis of the urban growth of Madrid during the last quarter of the XX century. Lett. Spat. Resour. Sci. 2017, 10, 205-214. [CrossRef]

24. Usach, N.; Garrido-Yserte, R.; Gallo-Rivera, T. Organización territorial y funcional de la metrópoli de Buenos Aires. EURE Rev. Latinoam. Estud. Urbano Reg. 2017, 43, 55-80. [CrossRef]

25. Jenks, M.; Burton, E.; Willians, K. The Compact City: A Sustainable Urban Form; E\&FN Spon: London, UK, 1996.

26. Bruegmann, R. Sprawl: A Compact History; University of Chicago Press: Chicago, IL, USA, 2006.

27. Ewing, R. Is Los Angeles-style sprawl desirable? J. Am. Plan. Assoc. 1997, 63, 107-126. [CrossRef]

28. Breheny, M. Centrist, decentriscts and compromisers: Views on the future of urban form. In The Compact City: A Sustainable Urban Form; Jenks, M., Burton, E., Willians, K., Eds.; E\&FN Spon: London, UK, 1996.

29. Camagni, R.; Capello, R.; Nijkamp, P. Towards sustainable city policy: An economy-environment technology nexus. Ecol. Econ. 1998, 24, 103-118. [CrossRef]

30. Wilson, B.; Chakraborty, A. The environmental impacts of sprawl: Emergent themes from the past decade of planning research. Sustainability 2013, 5, 3302-3327. [CrossRef]

31. Briggs, X.S. More pluribus, less Unum? The changing geography of race and opportunity. In Geography of Opportunity: Race and Housing Choice in Metropolitan America; The Brookings Institute: Washington, DC, USA, 2005; pp. 17-41.

32. Axelrod, J.B.C. Keep the L out of Los Angeles: Race, discourse and urban modernity in 1220 s southern California. J. Urban Hist. 2007, 34, 3-37. [CrossRef]

33. Florida, R.; Mellander, C. Exploring creativity and urban development with agent-based modeling. J. Artif. Soc. Soc. Simul. 2015, 18, 1-12.

34. Frumkin, H. Urban sprawl and public health. Public Health Rep. 2002, 117, 201-217. [CrossRef]

35. Ewing, R.; Pendall, R.; Chen, D. Measuring Sprawl and Its Impact: Smart Growth America; Transportation Research Board of the National Academies: Washinton, DC, USA, 2002.

36. Kotchen, M.; Schutle, S. A meta-analysis of cost community service studies. Int. Reg. Sci. Rev. 2009, 32, 376-399. [CrossRef]

37. Sole-Ollé, A. The effects of party competition on budges outcomes: Empirical evidence from local government in Spain. Public Choice 2006, 126, 145-176. [CrossRef]

38. Bosh, N.; Solé-Ollé, A. Yardstick competition and the political costs of raising taxes: An empirical analysis of Spanish municipalities. Tax Public Financ. 2007, 14, 71-92. [CrossRef]

39. Carruthers, J.I.; Ulfarsson, G.F. Does smart growth matter to public finance? Evidence from the United States. Urban Stud. 2008, 45, 1791-1823. [CrossRef]

40. Hasse, J.E.; Lathrop, R.G. Land resource impact indicators of urban sprawl. Appl. Geogr. 2003, 23, $159-175$. [CrossRef]

41. Robinson, L.; Newell, J.P.; Marzluff, J.M. Twenty-five years of sprawl in the Seattle region: Growth management responses and implications for conservation. Landsc. Urban Plan. 2005, 71, 51-72. [CrossRef]

42. Abu Hatab, A.; Cavinato, M.E.R.; Lindermer, A. Urban sprawl, food security and agricultural systems in developing countries: A systematic review if the literature. Cities 2019, 94, 129-142. [CrossRef]

43. Vicenzotti, V.; Qvistrom, M. Zwischenstadt as travelling concept: Towards a critical discussion of mobile ideas in transnational planning discourses on urban sprawl. Eur. Plan. Stud. 2018, 26, 115-132. [CrossRef]

44. Slemp, C.; Davenport, M.A.; Seekamp, E. Growing too fast: Local stakeholders speak out about growth and its consequences for community well-being in the urban-rural interface. Landsc. Urban Plan. 2012, 106, 139-148. [CrossRef]

45. Dupras, J.; Marull, J.; Parcerisas, L.; Coll, F.; Gonzalez, A.; Girard, M.; Tello, E. The impacts of urban sprawl on ecological connectivity in the Montreal Metropolitan Region. Environ. Sci. Policy 2016, 58, 61-73. [CrossRef]

46. Vimal, L.; Geniaux, G.; Pluvinet, P.; Napoleone, C.; Lepart, J. Detecting threatened biodiversity by urbanization at regional and local scales using an urban sprawl simulation approach: Application on the French Mediterranean region. Landsc. Urban Plan. 2012, 104, 343-355. [CrossRef]

47. Yan, X.P. Chinese urban geography since the late 1970s. Urban Geogr. 1995, 16, 469-492. [CrossRef] 
48. Yang, Y.; Zhang, L.; Ye, Y. Curbing sprawl with developing limiting boundaries in urban China: A review of literature. J. Plan. Lit. 2019, 35, 25-40. [CrossRef]

49. Johnson, M.P. Environmental impacts of urban sprawl: A survey of the literature and proposed research agenda. Environ. Plan. A 2001,33,717-735. [CrossRef]

50. Camagni, R.; Gibelli, M.C.; Rigamonti, P. Urban mobility and urban form: The social and environmental costs of different patterns of urban expansion. Ecol. Econ. 2002, 40, 199-216. [CrossRef]

51. Lee, B. Edge or edgeless cities? Urban spatial structure in US metropolitan areas, 1980 to 2000. J. Reg. Sci. 2005, 47, 479-515. [CrossRef]

52. Anas, A.; Rong, X. Congestion, land use, and job dispersion: A general equilibrium model. J. Urban Econ. 1999, 45, 451-473. [CrossRef]

53. Schneider, A.; Woodcock, C.E. Compact, dispersed, fragmented, extensive? A comparison of urban growth in twenty-five global cities using remotely sensed data, pattern metrics and census information. Urban Stud. 2008, 45, 659-692. [CrossRef]

54. Glaeser, E.; Kohlhase, J.E. Cities, regions and the decline of transport cost. Pap. Reg. Sci. 2004, 83, 197-228. [CrossRef]

55. Southworth, F. On the potential impacts of land use change policies on automobile vehicle miles of travel. Energy Policy 2001, 29, 1271-1283. [CrossRef]

56. Kim, J.; Brownstone, D. The impact of residential density on vehicle usage and fuel consumption: Evidence from national samples. Energy Econ. 2013, 40, 196-206. [CrossRef]

57. Su, Q.; DeSalvo, J.S. The effect of transportation subsides on urban sprawl. J. Reg. Sci. 2008, 48, 567-594. [CrossRef]

58. István, L.B. Urban sprawl and climate change: A statistical exploration of cause and effect, with policy options for the EU. Land Use Policy 2010, 27, 283-292.

59. Coq, D.; Asian, R. Urban sprawl and sustainable urban policies. A review of the cases of Lima, Mexico City and Santiago de Chile. Sustainability 2019, 11, 5835.

60. Xu, G.; Jiao, L.; Liu, J. Understanding urban expansion combining macro patterns and micro dynamics in three Southeast Asian megacities. Sci. Total Environ. 2019, 660, 365-383. [CrossRef]

61. Wiesmann, D.; Lima-Azevedo, I.; Ferrão, P.; Fernández, J.E. Residential electricity consumption in Portugal: Findings from top-down and bottom-up models. Energy Policy 2011, 39, 2772-2779. [CrossRef]

62. Stiri, H. Building and household X-factors and energy consumption at the residential sector. A structural equation analysis of the effects of household and building characteristics on the annual energy consumption of US residential buildings. Energy Econ. 2014, 43, 178-184.

63. Heinonen, J.; Junnila, S. Residential energy consumption patterns and the overall housing energy requirements of urban and rural households in Finland. Energy Build. 2014, 76, 295-303. [CrossRef]

64. Huang, W.H. The determinants of household electricity consumption in Taiwan: Evidence from quantile regression. Energy 2015, 87, 120-133. [CrossRef]

65. Lasarte, E.; Rubiera, F.; Cuartas, B.M. Energy consumption and urban sprawl: Evidence for the Spanish case. J. Clean. Prod. 2018, 172, 3479-3486.

66. Sarkar, C.; Webster, C. Healthy Cities of Tomorrow: The Case for Large Scale Built Environment-Health Studies. J. Urban Health 2017, 94, 4-19. [CrossRef] [PubMed]

67. Koprowska, K.; Laszkiewicz, E.; Kronenberg, J. Is urban sprawl linked to green space availability? Ecol. Indic. 2020, 108, 105723. [CrossRef]

68. Gruebner, O.; Rapp, M.A.; Adli, M.; Kluge, U.; Galea, S.; Heinz, A. Cities and Mental Health. Dtsch. Ärzteblatt Int. 2017, 114, 121-127. [CrossRef] [PubMed]

69. Dovey, K.; Symons, F. Density without Intensity and What to Do about It: Reassembling Public/Private Interfaces in Melbourne's Southbank Hinterland. Aust. Plan. 2014, 51, 34-46. [CrossRef]

(C) 2020 by the authors. Licensee MDPI, Basel, Switzerland. This article is an open access article distributed under the terms and conditions of the Creative Commons Attribution (CC BY) license (http://creativecommons.org/licenses/by/4.0/). 